\title{
Prevalence and risk factors for nasopharyngeal carriage of Streptococcus pneumoniae among adolescents
}

\section{Correspondence}

Cristiana M. Nascimento-Carvalho nascimentocarvalho@hotmail.com

Received 27 June 2007

Accepted 30 September 2007
Déa M. Cardozo, ${ }^{1}$ Cristiana M. Nascimento-Carvalho, ${ }^{1}$ Ana-Lúcia S. S. Andrade, ${ }^{2}$ Anníbal M. Silvany-Neto, ${ }^{3}$ Carla H. C. Daltro, ${ }^{4}$ Maria-Angélica S. Brandão, ${ }^{5}$ Angela P. Brandão ${ }^{6}$ and Maria-Cristina C. Brandileone ${ }^{6}$

${ }^{1}$ Department of Paediatrics, School of Medicine, Federal University of Bahia, Avenida Reitor Miguel Calmon, s/n, CEP 40110-100, Salvador, Bahia, Brazil

${ }^{2}$ Institute of Tropical Pathology and Public Health, Federal University of Goiás, Goiânia, Goiás, Brazil ${ }^{3}$ Department of Preventive Medicine, School of Medicine, Federal University of Bahia, Salvador, Bahia, Brazil

${ }^{4}$ Bahiana School of Medicine and Public Health, Salvador, Bahia, Brazil

${ }^{5}$ Central Laboratory of Bahia (LACEN), Salvador, Bahia, Brazil

${ }^{6}$ Bacteriology Branch, Adolfo Lutz Institute (IAL), São Paulo, Brazil

Data on the prevalence of pneumooccal nasopharyngeal carriage and its risk factors among adolescents are scarce. The aim of this study was to provide such information. A cross-sectional, population-based prospective study was conducted. Participants were 1013 adolescents (age range 10-19 years) randomly recruited in 22 public schools. Those schools were randomly chosen among 307 public schools from 11 Sanitary Districts of Salvador, Brazil. Nasopharyngeal samples were assessed by standard procedures to recover and identify Streptococcus pneumoniae. Data on potential risk factors were gathered by confidential interview based on a standardized questionnaire. Pneumococci were recovered from 8.2\% [83/1013, $95 \%$ confidence interval (Cl) 6.6-10.0]. By stepwise logistic regression, pneumococcal colonization was independently associated with younger age [odds ratio (OR) $0.85,95 \% \mathrm{Cl} 0.77-0.94$, $P=0.001$ ], being male (OR $1.78,95 \% \mathrm{Cl} 1.11-2.85, P=0.02$ ), exposure to passive smoke in the household (OR 1.76, $95 \% \mathrm{Cl} 1.10-2.79, P=0.02$ ), having an upper respiratory infection during recruitment (OR 2.67, $95 \% \mathrm{Cl} 1.67-4.28, P<0.001$ ) and having a history involving an episode of acute asthma during the last year (OR 2.89, $95 \% \mathrm{Cl} 1.18-7.08, P=0.03$ ). The estimated probability of pneumococcal colonization decreased with age $\left(\chi^{2}\right.$ for trend $=8.52$, $P=0.003)$. These findings provide tools for increasing the use of prevention strategies for pneumococcal diseases, such as pneumococcal vaccination among asthmatic patients and public health measures to stop smoking.

\section{INTRODUCTION}

The incidence of invasive pneumococcal disease is highest among children and the elderly (CDC, 1997). However, respiratory infections are an important cause of morbidity and mortality among adolescents (Benguigui, 1992). Among children, Streptococcus pneumoniae is a major causative agent of such infections (Heiskanen-Kosma et al., 1998). The nasopharynx is known to be the main ecological

Abbreviations: CDC, Centers for Disease Control and Prevention; $\mathrm{Cl}$, confidence interval; OR, odds ratio. reservoir of S. pneumoniae, from where it can give rise to disease after extending to other areas of the respiratory tract or penetrating normally sterile body fluids (Austrian, 1986). Although nasopharyngeal isolates are not useful for predicting the causative agent of invasive disease in individuals, they reflect epidemiological aspects of pneumococcal disease in the community (Brueggemann et al., 2003).

Studies conducted over the last decades have gradually revealed the connection between pneumococcal carriage, and mucosal and invasive infections caused by the 
organism (Bogaert et al., 2004a), and identified young age (Austrian, 1986), viral respiratory infections (Avadhanula et al., 2006) and day-care centre attendance (Bogaert et al., 2004b) as risk factors for both nasopharyngeal colonization and occurrence of disease in children. Because the burden of pneumococcal disease is lower in adolescents, the carriage of the organism in this section of the population has not been explored in depth. Basic knowledge of this is important for understanding the transmission patterns of pneumococci in families and communities. The aims of this study were to provide data on the prevalence of nasopharyngeal carriage and on conditions predisposing pneumococcal colonization among adolescents.

\section{METHODS}

Sampling. This cross-sectional survey was conducted in Salvador, North-East Brazil, from November 2002 to July 2003. A single nasopharyngeal specimen was collected from adolescents (between 10 and 19 years of age) (PAHO, 1998) from public schools. The city has a total of 307 public schools distributed among 11 Sanitary Districts. The list of all the public schools by Sanitary District was obtained from the Secretariat of Education of Salvador. A two-sample stage sampling was applied to select participant adolescents. Two schools from each District were randomly chosen. The number of adolescents registered at each studied school ranged from 1200 to 7530 , and the number of adolescents recruited by school varied between 88 and 104 . The sample size was estimated taking into account the expected pneumococcal carriage for adults (Inostroza et al., 1998). Thus, we estimated that 900 participants would be sufficient to detect a prevalence and the respective $95 \%$ confidence interval (CI) of nasopharyngeal colonization ranging from $8-12 \%$ (point prevalence $=10 \%, 2 \%$ error). We assumed a $12 \%$ refusal to participate, so the sample size was established as 1000 participants. Demographic, clinical and epidemiological data were collected by a standardized questionnaire.

Bacteriological data. Two trained biochemists collected nasopharyngeal specimens by rotating cotton-tipped flexible swabs (Transwab pernasal charcoal medium; Medical Wire \& Equipment)) during the smooth insertion through the nostrils of each individual, whose head was tipped backward; the swabs were left in the posterior nasopharynx for $5 \mathrm{~s}$ to saturate the tip and then they were transported in Amies medium within $4 \mathrm{~h}$ to the Central Laboratory of Bahia where they were inoculated onto trypticase soy agar with added $5 \%$ sheep blood and $5 \mu \mathrm{g}$ gentamicin $\mathrm{ml}^{-1}$. Plates were incubated at $37{ }^{\circ} \mathrm{C}$ in $5 \% \mathrm{CO}_{2}$ for 18 to $24 \mathrm{~h}$. Micro-organisms whose colonies displayed pneumococcus morphology (Gram stain) and that were susceptible to a $5 \mu \mathrm{g}$ optochin disc (inhibition zone $\geqslant 14 \mathrm{~mm}$ ) and had bile solubility were defined as pneumococcus. All strains were frozen in skim milk and transported in dry ice by airplane to the Bacteriology Branch, Adolfo Lutz Institute, where the identification was confirmed by the same procedures. Collection of samples and laboratory procedures were performed in accordance with World Health Organization guidelines (WHO, 1994).

Data analysis. All data were entered into a database using Epi Info 6.04. Descriptive analysis was performed by SPSS package (version 9.0) and STATA software (version 8.0) was applied for logistic regression analysis. The rainy season was defined as the period between April and September, and the dry season as the period between October and March. Rain is the main difference between seasons in the study area. Prevalence rates and the respective 95\% CI were calculated. Association between categorical variables was initially tested by univariate analysis with the Pearson chi-square or Fisher's exact test, when appropriate. Means of continuous variables were compared by Student $t$-test or Mann-Whitney $\mathrm{U}$ test, as appropriate. A $P$ value $<0.05$ was considered significant and all tests were two-tailed tests. Potential variables associated with pneumococcal carriage were assessed by odds ratio (OR) with the respective $95 \%$ CI. Independent variables that gave significant or borderline results in the univariate analysis were used in a four stepwise multiple logistic regression analysis to determine their independent effect on pneumococcal nasopharyngeal carriage. This multivariate analysis allowed the examination of the effects of all exposure variables reciprocally and simultaneously adjusting for all the other variables in the model. All possible interactions were assessed. After the written consent of the director of the school, each adolescent was exposed to a brief explanation about this investigation and he/she was requested to give written informed consent before recruitment. This procedure was based on the assumption of the low risk of this investigation and on the capacity of an adolescent to provide informed consent in such a situation (Santelli et al., 2003). The ethics committees of the participating institutions approved the study.

\section{RESULTS AND DISCUSSION}

We collected nasopharyngeal swabs from 1013 adolescents (age range 10-19 years, mean $14.6 \pm 2.3$ years). Twenty adolescents refused to consent to take part in the study and were replaced using the same procedure of random selection. Pneumococcus was recovered from 83 samples $(8.2 \%, 95 \%$ CI 6.6-10.0) and the estimated probability of pneumococcal colonization decreased with age (Table 1). Data on antimicrobial resistance and serotype distribution have been presented elsewhere (Cardozo et al., 2006b). Most studies evaluating pneumococcal nasopharyngeal carriage enrolled only children (O'Brien et al., 2003). In Brazil, pneumococcal colonization rates in children aged 8-71 months have ranged from 21.2-55.0\% (Cardozo et al., 2006a). A few studies have analysed adolescents along with children (Bogaert et al., 2004b; Inostroza et al., 1998; Ciftçi et al., 2000; Muhlemann et al., 2003; Hussain et al., 2005)

Table 1. Prevalence of nasopharyngeal pneumococcal colonization among Brazilian adolescents by age in years

The $\chi^{2}$ value for the trend is $8.52, P$ value $=0.003$.

\begin{tabular}{|lcc|}
\hline \multirow{2}{*}{$\begin{array}{l}\text { Age } \\
\text { (years) }\end{array}$} & \multicolumn{2}{c|}{ Pneumococcal carrier } \\
\cline { 2 - 3 } & $\boldsymbol{n}$ /total & Percentage $(95 \%$ CI $)$ \\
\hline 10 & $5 / 43$ & $11.6(3.9-25.1)$ \\
11 & $7 / 62$ & $11.3(4.7-21.9)$ \\
12 & $11 / 94$ & $11.7(6.0-20.0)$ \\
13 & $12 / 117$ & $10.3(5.4-17.2)$ \\
14 & $13 / 138$ & $9.4(5.1-15.6)$ \\
15 & $14 / 154$ & $9.1(5.1-14.8)$ \\
16 & $10 / 179$ & $5.6(2.7-10.0)$ \\
17 & $7 / 116$ & $6.0(2.5-12.0)$ \\
18 & $3 / 72$ & $4.2(0.9-11.7)$ \\
19 & $1 / 38$ & $2.6(0.06-13.8)$ \\
Total & $83 / 1013$ & $8.2(6.6-10.0)$ \\
\hline
\end{tabular}


or the whole population (Hennessy et al., 2002), reporting prevalence of pneumococcal carriage from 19 to $43 \%$. These studies do not allow proper evaluation of adolescents (PAHO, 1998), and thus are lacking the identification of risk factors. The pneumococcal carriage rate reported herein was similar to the rate reported by Hussain et al. (2005) for people aged $\geqslant 18$ years $(8 \%)$, but an independent association of age with pneumococcal colonization was found, that is, the younger the adolescent the greater the risk of pneumococcal colonization (Table 1). A similar finding was observed by Bogaert et al. (2004b), although those authors have not analysed statistically the trend of colonization rate through adolescence. Colonization of the nasopharynx may be detected in early infancy, with a peak incidence during the first 3 years of life (Bogaert et al., 2004a). It has been demonstrated that infants $<2$ months of age and adults aged 18 to 50 years are the age groups with the lowest nasopharyngeal pneumococcal carriage rates (Dagan et al., 1998). Therefore, one can infer that age is an important risk factor for pneumococcal colonization and its influence varies with the phase of growth throughout life.
The frequency of the baseline characteristics of the study group and the significant differences in relation to pneumococcal isolation are presented in Table 2. The maximum number of children aged less than 5 years in the same sleeping room was two. No significant differences were found in all other searched variables when compared with pneumococcal carriage, including underlying diseases (immunodeficiency 2.4 vs $2.1 \%$, sickle cell disease 1.3 vs $1.8 \%$, diabetes mellitus 0 vs $0.9 \%$, chronic lung disease 1.2 vs $0.8 \%$ or liver disease 0 vs $0.5 \%$ ). Two, one and no individuals reported cardiac disease, renal disease and human immunodeficiency virus infection, respectively. The frequency of nasal medicine use during the previous $24 \mathrm{~h}$ was the same (1.2\%) among pneumococcal colonized and non-colonized adolescents. The isolation rates were statistically similar in the rainy $(8.6 \%)$ and the dry (7.5\%) season. Being of the male sex has been described as an independent risk factor for more frequent and more severe lower respiratory infections (Falagas et al., 2007). In this investigation, males were significantly more likely to be pneumococcal carriers than females (Table 2). The higher probability to have respiratory

Table 2. Baseline characteristics for 1013 Brazilian adolescents and potential factors associated with pneumococcal carriage

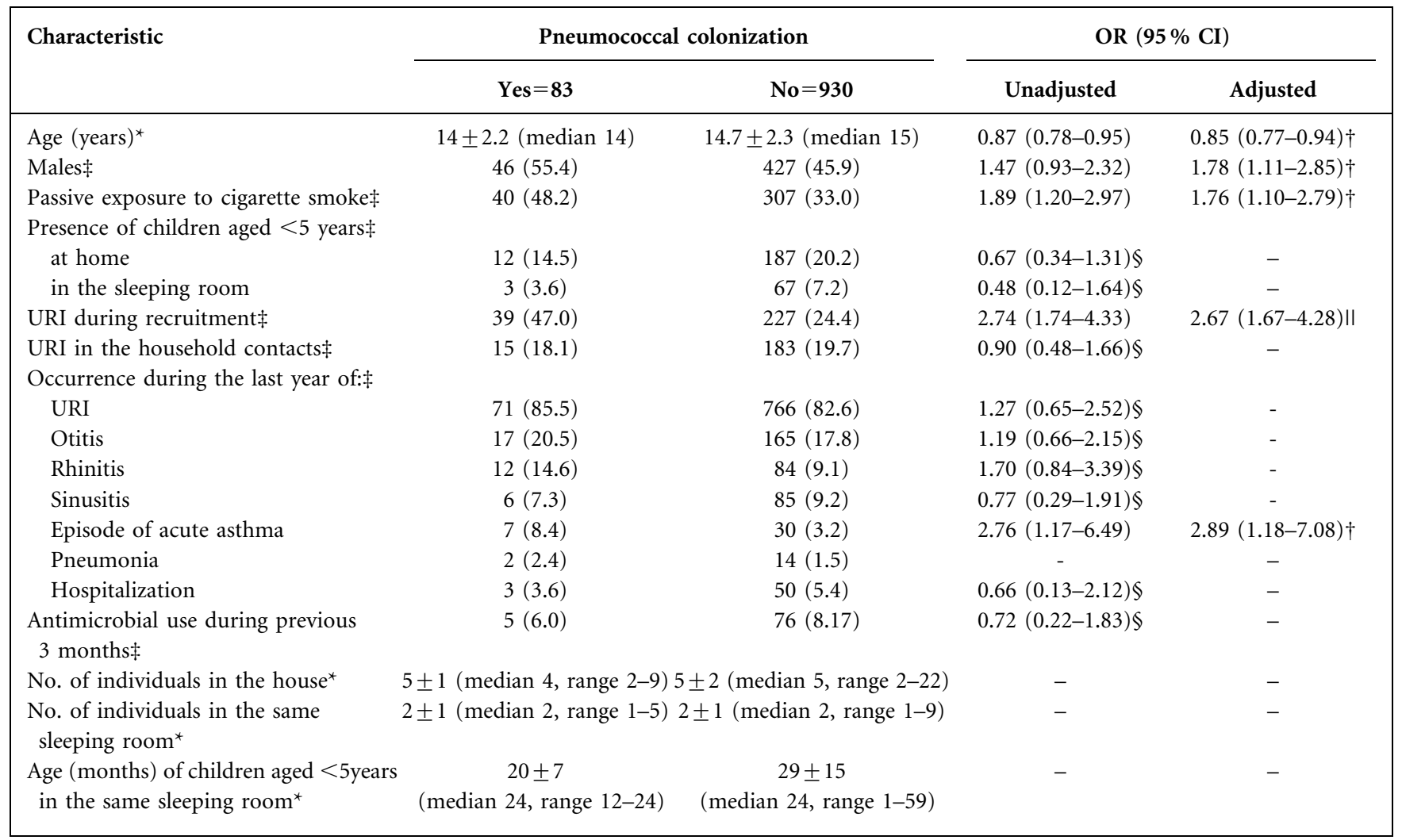

URI, Upper respiratory infection.

${ }^{\star}$ Results as continuous variables.

$\dagger P$ value $<0.05$.

$\ddagger$ Results are reported as $n(\%)$.

$\S P$ value $>0.05$; log likelihood ratio test.

II $P$ value $<0.001$. 
disease may be partly secondary to the higher probability to be colonized.

Among non-smoking adolescents, exposure to tobacco smoke in the household was associated with pneumococcal carriage (47.6 vs $32.8 \%, P<0.01$ ); among 13 active smoking adolescents, pneumococcus was recovered from one person who also reported exposure to passive smoke in the household $(100 \%, 1 / 1)$; among 12 smokers noncolonized by pneumococcus, exposure to passive smoke was reported by $6(50 \%)$. Our findings present evidence that asthmatic individuals are independently more prone to be pneumococcal carriers (Table 2). In a recent study, Talbot et al. (2005) identified asthma as an independent risk factor for invasive pneumococcal disease in people aged 2-49 years. Nonetheless, exposure to tobacco was not measured in that study. In our study, the stratified evaluation included asthma and passive exposure to tobacco (Table 2), and each of them was identified as an independent risk factor for pneumococcal colonization. The association of exposure to tobacco and pneumococcal carriage in children and their mothers has been demonstrated (Greenberg et al., 2006). Cigarette smoking has been identified as the strongest factor for invasive pneumococcal disease among immunocompetent, nonelderly adults (Nuorti et al., 2000). Contact with smokers has also been identified as a risk factor for meningococcal disease in adolescents (Coen et al., 2006). In this last study, the authors differentiated the exposure to smoke from exposure to smokers, and the first variable was not associated with meningococcal disease. It is supposed that smokers may be more infectious than non-smokers (Nuorti et al., 2000).

The preceding data show evidence that asthma and exposure to tobacco are independent risk factors for pneumococcal carriage. The conjugate pneumococcal vaccine decreases pneumococcal carriage (O'Brien \& Dagan, 2003) and it has proven to be effective in preventing invasive disease (Black et al., 2006). Our findings emphasize the inclusion of asthma as a condition for the use of pneumococcal vaccine, in addition to the evidence that asthmatic patients have a higher risk of invasive pneumococcal disease (Talbot et al., 2005). Measures to prevent cigarette smoking should include information regarding the risk of pneumococcal carriage and invasive disease.

According to the Advisory Committee on Immunization Practices (ACIP, 2000), conjugate pneumococcal vaccine has not been studied sufficiently among older children or adults to make recommendations for its use among persons aged $\geqslant 5$ years. The results observed in the present investigation are aligned with previous studies that found asthma as an important risk factor for invasive pneumococcal disease (Talbot et al., 2005). Thus, adolescents should be considered a potential group that deserves consideration regarding the investigation of pneumococcal morbidity and conjugate vaccine efficacy. Further studies conducted in other regions should be instigated in order to confirm our findings.

\section{ACKNOWLEDGEMENTS}

The authors are in debt to Professor Maria Regina Alves Cardoso for her review of the multivariate analysis. This study received financial support from FAPESB (Foundation to Support Research in Bahia State, Brazil). A.-L. S. S. A. was the recipient of a fellowship (grant no. 308043/2004-9) from the Brazilian National Council for Scientific and Technological Development (CNPq).

\section{REFERENCES}

ACIP (2000). Preventing pneumococcal disease among infants and young children. Recommendations of the Advisory Committee on Immunization Practices (ACIP). MMWR Recomm Rep 49 (RR-9), 1-35.

Austrian, R. (1986). Some aspects of the pneumococcal carrier state. J Antimicrob Chemother 18 (Suppl. A), 35-45.

Avadhanula, V., Rodríguez, C. A., Devincenzo, J. P., Wang, Y., Webby, R. J., Ulett, G. C. \& Adderson, E. E. (2006). Respiratory viruses augment the adhesion of bacterial pathogens to respiratory epithelium in a viral species- and cell type-dependent manner. J Virol 80, 1629-1636.

Benguigui, Y. (1992). Acute respiratory infections. In Manual of Medicine of Adolescence, 1st edn, pp. 225-228. Edited by T. J. Silber, M. M. Munist, M. Maddaleno \& E. N. S. Ojeda. Washington, DC: Pan American Health Organization.

Black, S., Shinefield, H., Baxter, R., Austrian, R., Elvin, L., Hansen, J., Lewis, E. \& Fireman, B. (2006). Impact of the use of heptavalent pneumococcal conjugate vaccine on disease epidemiology in children and adults. Vaccine 24 (Suppl 2), 79-80.

Bogaert, D., Groot, R. \& Hermans, P. W. M. (2004a). Streptococcus pneumoniae colonization: the key to pneumococcal disease. Lancet Infect Dis 4, 144-154.

Bogaert, D., Belkum, A., Sluijter, M., Luijendijk, A., Groot, R., Rumke, H. C., Verbrugh, H. A. \& Hermans, P. W. M. (2004b). Colonization by Streptococcus pneumoniae and Staphylococcus aureus in healthy children. Lancet 363, 1871-1872.

Brueggemann, A. B., Griffiths, D. T., Meats, E., Peto, T., Crook, D. W. \& Spratt, B. G. (2003). Clonal relationship between invasive and carriage Streptococcus pneumoniae and serotype- and clone-specific differences in invasive disease potential. J Infect Dis 187, 1424-1432.

Cardozo, D. M., Nascimento-Carvalho, C. M., Souza, F. R. \& Silva, N. M. S. (2006a). Nasopharyngeal colonization and penicillin resistance among pneumococcal strains: a world-wide 2004 update. Braz J Infect Dis 10, 293-304.

Cardozo, D. M., Nascimento-Carvalho, C. M., Brandão, M. A., Azevedo, G. M. S., Souza, F. R., Silva, N. M. S., Brandão, A. P., Andrade, A.-L. S. S. \& Brandileone, M. C. C. (2006b). Antimicrobial resistance and serotypes of nasopharyngeal strains of Streptococcus pneumoniae in Brazilian adolescents. Microb Drug Resist 12, 29-32.

CDC (1997). Prevention of pneumococcal disease: recommendations of the Advisory Committee on Immunization Practices (ACIP). MMWR Morb Mortal Wkly Rep 46, 1-24.

Ciftçi, E., Dogru, U., Aysev, D., Ince, E. \& Guriz, H. (2000). Nasopharyngeal colonization with penicillin-resistant Streptococcus pneumoniae in Turkish children. Pediatr Int 42, 552-556.

Coen, P. G., Tully, J., Stuart, J. M., Ashby, D., Viner, R. M. \& Booy, R. (2006). Is it exposure to cigarette smoke or to smokers which 
increases the risk of meningococcal disease in teenagers? Int $J$ Epidemiol 35, 330-336.

Dagan, R., Shriker, O., Hazan, I., Leibovitz, E., Greenberg, D., Schlaeffer, F. \& Levy, R. (1998). Prospective study to determine clinical relevance of detection of pneumococcal DNA in sera of children by PCR. J Clin Microbiol 36, 669-673.

Falagas, M. E., Mourtzoukou, E. G. \& Vardakas, K. Z. (2007). Sex differences in the incidence and severity of respiratory tract infections. Respir Med 101, 1845-1863.

Greenberg, D., Givon-Lavi, N., Broides, A., Blancovich, I., Peled, N. \& Dagan, R. (2006). The contribution of smoking and exposure to tobacco smoke to Streptococcus pneumoniae and Haemophilus influenzae carriage in children and their mothers. Clin Infect Dis 42, 897-903.

Heiskanen-Kosma, T., Korppi, M., Jokinen, C., Kurki, S., Heiskanen, L., Juvonen, H., Kallinen, S., Stén, M., Tarkiainen, A. \& other authors (1998). Etiology of childhood pneumonia: serological results of a prospective population-based study. Pediatr Infect Dis J 17, 986-991.

Hennessy, T. W., Petersen, K. M., Bruden, D., Parkinson, A. J., Hurlburt, D., Getty, M., Schwartz, B. \& Butler, J. C. (2002). Changes in antibiotic-prescribing practices and carriage of penicillin-resistant Streptococcus pneumoniae: a controlled intervention trial in rural Alaska. Clin Infect Dis 34, 1543-1550.

Hussain, M., Melegaro, A., Pebody, R. G., George, R., Edmunds, W. J., Talukdar, R., Martin, S. A., Efstratiou, A. \& Miller, E. (2005). A longitudinal household study of Streptococcus pneumoniae nasopharyngeal carriage in a UK setting. Epidemiol Infect 133, 891-898.

Inostroza, J., Trucco, O., Prado, V., Vinet, A. M., Retamal, G., Ossa, G. Facklam, R. R. \& Sorensen, R. U. (1998). Capsular serotype and antibiotic resistance of Streptococcus pneumoniae isolates in two Chilean cities. Clin Diagn Lab Immunol 5, 176-180.
Muhlemann, K., Matter, H. C., Tauber, M. G. \& Bodmer, T. (2003). Nationwide surveillance of nasopharyngeal Streptococcus pneumoniae isolates from children with respiratory infection, Switzerland, 19981999. J Infect Dis 187, 589-596.

Nuorti, J. P., Butler, J. C., Farley, M. M., Harrison, L. H., McGeer, A., Kolczak, M. S. \& Breiman, R. F. for The Active Bacterial Core Surveillance Team (2000). Cigarette smoking and invasive pneumococcal disease. $N$ Engl J Med 342, 681-689.

O'Brien, K. L. \& Dagan, R. (2003). The potential indirect effect of conjugate pneumococcal vaccines. Vaccine 21, 1815-1825.

O'Brien, K. L. \& Nohynek, H. \& WHO Pneumococcal Vaccine Trials Carriage Working Group (2003). Report from a WHO working group: standard method for detecting upper respiratory carriage of Streptococcus pneumoniae. Pediatr Infect Dis J 22, 133-140.

PAHO (1998). Plan of Action on Health and Development of Adolescent and Youth in the Americas, 1998-2001. Washington, DC: Pan American Health Organization.

Santelli, J. S., Rogers, A. S., Rosenfeld, W. D., DuRant, R. H., Dubler, N., Morreale, M., English, A., Lyss, S., Wimberly, Y. \& Schissel, A. (2003). Guidelines for adolescent health research: a position paper of the Society for Adolescent Medicine. J Adolesc Health 33, 396-409.

Talbot, T. R., Hartert, T. V., Mitchel, E., Halasa, N. B., Arbogast, P. G., Poehling, K. A., Schaffner, W., Craig, A. S. \& Griffin, M. R. (2005). Asthma as a risk factor for invasive pneumococcal disease. $N$ Engl $J$ Med 352, 2082-2090.

WHO (1994). Manual for the National Surveillance of Antimicrobial Resistance of Streptococcus pneumoniae and Haemophilus influenzae: Epidemiological and Microbiological Methods. Geneva: World Health Organization. 